\title{
Exploring the Effect of Venture Capital Instruments and Control Mechanisms on Growth of Venture Capital Fund: Empirical Evidence from Ghana
}

\author{
Suweiba Sulemana, Haibo Chen* \\ School of Finance and Economics, Jiangsu University, Zhenjiang, China \\ Email: ^hbchen@ujs.edu.cn
}

How to cite this paper: Sulemana, S. and Chen, H.B. (2019) Exploring the Effect of Venture Capital Instruments and Control Mechanisms on Growth of Venture Capital Fund: Empirical Evidence from Ghana. Open Journal of Business and Management, 7, 180-193.

https://doi.org/10.4236/ojbm.2019.71013

Received: December 6, 2018

Accepted: January 8, 2019

Published: January 11, 2019

Copyright $\odot 2019$ by author(s) and Scientific Research Publishing Inc. This work is licensed under the Creative

Commons Attribution International License (CC BY 4.0).

http://creativecommons.org/licenses/by/4.0/

\begin{abstract}
The study investigated the effect of venture capital instruments and control mechanisms on the growth of venture capital fund for 100 venture capital firms in Ghana by employing a stepwise multiple linear regression. We found a positive and significant relationship between growth of venture capital fund and the two-distinct set of independent variables (venture capital instruments and control mechanisms). The variables, convertible redeemable preference, preferred equity and debt, and preferred and common equity contribute significantly as venture capital instruments to the growth of venture capital, while conversion control right, performance option and warranty option were identified as control mechanisms that significantly affect the growth of venture capital.
\end{abstract}

\section{Keywords}

Venture Capital, Control Mechanism, Instrument, Growth

\section{Introduction}

The growing importance of Venture Capital in the life of start-up businesses, particularly technologically focused ones cannot be overemphasized. Usually, patterns of the investment capitalists strategic decision-making process are based on the knowledge acquired, and this takes the shape of diversification as the venture capitalisation gains experience over time in a given business environment. In this case, venture capital firms use their long-term experience in controlling possible investment risks while at the same time maintaining high 
returns. This is achieved in two main ways, through specialisation and diversification in company growth stages, geographic location and across industries. Venture capitalists therefore identify, evaluate and invest in high risk business investments that limited partners find challenging to invest indirectly. It should, however, be noted that the venture capital industry has evolved from an ad hoc collection of pioneering investors into now a sophisticated, fast paced and highly specialised industry. When considering the high degree of uncertainty involved in the venture capital industry, one should consider that rational decision-making model; which are only one way of coping with uncertainty.

In third world countries like Ghana, venture capital industry started with an informal style of operations in early 2000 by private firms. Information about the industry also reveals that Private Equity style of activities had taken place in the county during the early 1990s through collaborative efforts between the United States Agency for Development (USAID) and the Commonwealth Development Cooperation (CDC) of the European Union (EU). Their main aim was to support Ghana's economic reform program called Financial Sector Adjustment Program. However, the process of formalizing the industry was realized in 2004, when the Ghanaian government enacted Act 680 through the parliament aiming at providing the legal and the regulatory framework for the establishment of a Venture Capital Trust Fund. This was mainly to address two main issues: to give the better environment that will enable development and promotion of a viable venture capital industry [1] and to ensure effective partnership with private firms for the provision of investment capital to Small and Medium-Term Enterprises [2].

The main challenge for start-up businesses is the lack of opportunities in securing funds through traditional investment sources such as banks [3] [4]. While some notable effort has been made to sustain venture capital financing to the SME sector, progress over the last decade has been slow, with limited impact [5] [6]. Venture capital is essential as far as business financing is concerned; especially in the case of start-ups and businesses that seek to expand. Long term financing in terms of equity capital, needed by growth-oriented, mainly small and medium companies, is virtually non-existent for SMEs in Ghana [7]. As a result, a high number of SMEs do access equity via family and friends as well as investors abroad. Ghana's economy and a fast growing one thus make it imperative to identify the various instruments and mechanisms being put in place in the establishment of venture capital which has the potential to develop new businesses and expand existing ones through the provision of capital.

The remainder of the study is organized as follows: Section 2 presents a brief review of literature; Section 3 gives information on data and methods used in the study; Section 4 focuses on the model specification followed by discussion of findings in Section 5; Section 6 concludes the study.

\section{Literature}

The characteristics of the venture capital firms have been studied by many scien- 
tists for more than 30 years. Various aspects of venture capital financing (such as value-added, monitoring, contracting, etc.) have a special interest in academic literature. In addition, most research has focused on the impact of venture capital markets on the economy, especially through financing for young and promising small and medium-sized enterprises (SMEs). Entrepreneurs often encounter obstacles at the beginning of their business. The most common is the lack of capital for financing products or company growth. Banks are too conservative to fund such companies because of the risks and lack of understanding of innovative ideas or products. Therefore, alternative investments such as venture capital funds or private investors (so-called business angels) are the right choice. Venture capitalists suffered as their investments became illiquid during the 2007 recession. As a result, venture capital markets are shrinking because venture capitalists are becoming more cautious about raising money for risky companies. Especially small countries like Ghana. The lack of venture capital financing has a huge aftereffect on the economy, as many fledgling companies can suffer losses and go bankrupt. Therefore, government intervention in venture capital funds can improve the reputation of venture capital funds and attract more funds investors.

In this case, venture capital firms use their long-term experience in controlling possible investment risks while at the same time maintaining high returns [8] [9] [10]. This can be achieved in two main ways, through specialisation and diversification in company growth stages, geographic location and across industries. Entrepreneurs have ideas requiring substantial financing so as implement them, however, many lack these funds [11]. Often, limited knowledge exists as to how venture capital firms can develop and implement their investment portfolios over time. In this case, the venture capitalists (VCs) come in handy as they represent one solution to financing projects of high risk but highly rewarding. Venture capitalists therefore identify, evaluate and invest in high risk business investments that limited partners find challenging to invest indirectly. It should, however, be noted that the venture capital industry evolved from an ad hoc collection of pioneering investors into now a sophisticated, fast paced and highly specialised industry. During this evolution period, venture capitalists provided fuel for entrepreneurs who created a generation of companies which have changed the face of the planet [12] [13] [14]. When considering the high degree of uncertainty involved in the venture capital industry, one should consider that rational decision-making model; which are only one way of coping with uncertainty. It was concluded that venture capitalists would usually engage in less logical processes of strategic decision-making when they are faced with decisions that are characterized by a high degree of uncertainty [15]. The rational decision-making models designed in a step-by-step and logical sequence have been used to describe the venture capital decision-making process [16] [17] [18]. During this evolution period, venture capitalists provided fuel for entrepreneurs who then created a generation of companies which have changed the face of the 
planet [19]. Venture capitalists would usually engage in less logical processes of strategic decision-making when they are faced with decisions that are characterized by a high degree of uncertainty. The rational decision-making models designed in a step-by-step and logical sequence have been used to describe the venture capital decision-making process [20].

Although, many aspects of this current topic have been analysed, see for example [21]-[27], there is lack researches dealing with the effect of venture capital instruments and control mechanisms on the growth of venture capital firms. In this gap this paper compared to other works investigates the determinants of growth of venture funds using venture capital instruments and control mechanisms through a multiple linear regression analysis.

\section{Data and Methods}

This study was conducted using both quantitative and explanatory research design. The quantitative research design aided the study to collect, group and also categorise data so as to allow statistical analysis. The explanatory research design on the other hand looks at how things come together and interact and also seeks to uncover causes and effects of interactions in order to find interpretation for a phenomenon. The source of data for the study was obtained from a primary source where well-structured questionnaires as research instrument were designed and administered to a staff and owners from a sample of selected firms in Ghana. Due to time and resource constraints, a sample of 100 venture capital firms was selected from the population of venture capital firms in Ghana by using the purposive sampling technique. The purposive sampling technique enabled us to choose firms who their opinions are relevant to the study. In exploring the effect of venture capital instruments and control mechanisms on the growth of venture capital fund, the sample of venture capital firms were chosen because they can provide adequate and useful information which in useful for this study. Raw data from a study is useless unless it is transformed into information meaningful for the purpose of the study. Thus, the raw data obtained from the administration of the questionnaires were gathered and analysed using multicolinearity test (Variance Inflation Factor (VIF)), and a multiple linear regression in order to investigate the effect of venture capital instruments and control mechanisms on the growth of venture capital funds of firms in Ghana. The data analysis was successfully performed by using SPSS 22.0.

\section{Model Specification}

This study utilizes a multiple linear regression to investigate the effect of venture capital instruments and other control mechanisms on the growth of venture capital fund using venture capital firms in Ghana. The multiple linear regression generally is used for estimating the relationship among variables. It includes techniques for modeling and analysing several variables, when the focus in on estimating the relationship between a dependent variables and more indepen- 
dent variables. Generally, a multiple linear regression with $p$ independent variables is mathematically formulated as:

$$
y_{i}=\beta_{0}+\beta_{1} x_{i 1}+\beta_{2} x_{i 2}+\ldots+\beta_{p} x_{i p}+\varepsilon
$$

where $x_{i j}$ represents the $i$ th observation on the $j$ th independent variable, $\beta_{0}$ represents the intercept, $y_{i}$ is the $i$ th observation of the dependent variable whereas $\beta_{1}, \beta_{2}, \ldots \beta_{p}$ captures the effects of the independent variables on the response variables (parameter estimates).

Base of the main objective of the study, the multiple regression model wherein growth of venture capital fund (VFC) is regressed on venture capital instruments (preferred equity and debt, convertible redeemable preference, preferred and common equity, debt, common equity, perceived failure and preferred equity) is specified as;

$$
\mathrm{VCF}=\beta_{o}+\beta_{1} \mathrm{PED}+\beta_{2} \mathrm{CRP}+\beta_{3} \mathrm{PCE}+\beta_{4} \mathrm{Dbt}+\beta_{5} \mathrm{CmE}+\beta_{6} \mathrm{PFP}+\beta_{6} \mathrm{PE}+\varepsilon(2)
$$

whereas the multiple regression where growth of venture capital is regressed on control mechanisms (conversion control right, veto management decision, performance options, preemptive control rights, warranty options, right to demand liquidation of assets and right to exit investment) is on the other hand also specified as;

$$
\mathrm{VCF}=\beta_{o}+\beta_{1} \mathrm{CCR}+\beta_{2} \mathrm{VMD}+\beta_{3} \mathrm{PO}+\beta_{4} \mathrm{PCR}+\beta_{5} \mathrm{WO}+\beta_{6} \mathrm{RD}+\beta_{7} \mathrm{REI}+\varepsilon
$$

where VCF represents venture capital growth, PED denotes preferred equity and debt, CRP is convertible redeemable preference, CRP represents convertible redeemable preference, PCE is preferred and common equity, Dbt means debt whilst CmE, PFP and PE are common equity, and perceived failure and preferred equity respectively. Also, from Equation (3) CCR, VMD, PO, PCR, WO, $\mathrm{RD}$, and REI respectively represents conversion control right, veto management decision, performance options, preemptive control rights, warranty options, right to demand liquidation of assets and right to exit investment.

The dependent variable in this study as mentioned already is VCF (venture capital fund) in most organizations or venture capital firms were measured by their total investment (TI) less than the investment from Private Sources (IPS) which is given mathematically by the relation:

$$
\mathrm{VCF}_{i}=\mathrm{IPS}_{i}-\mathrm{TI}_{i}
$$

where $i$ represents the individual firms that were selected for the study.

The independent variables were venture capital instruments and control mechanisms. These variables that were based on recommendations from previous researches were selected for use in this study. Seven variables each were combined to be a measure of venture instruments and control mechanisms respectively. Specifically, the variables; preferred equity and debt, convertible redeemable preference, preferred and common equity, debt, common equity, perceived failure and preferred equity were used to measure venture capital instruments whilst conversion control right, veto management decision, performance options, 
preemptive control rights, warranty options, right to demand liquidation of assets and right to exit investment on the other were used to measure control mechanisms.

\section{Results and Discussions}

\subsection{Summary of Descriptive Statistics and Multicolinearity Test}

A brief summary of the descriptive statistics is presented in Table 1 . With respect to our findings, the most important refers to the actual deviation from the mean value for the variables used in the study. To be more specific, the value of the standard deviation of the dependent variable is equal to 1.91. Furthermore the same statistics for Convertible redeemable preference, Preferred equity and debt, Preferred and common equity, Debt, Common equity, Perceived failure, and Preferred equity measuring venture capital instruments are respectively equal to $0.21,2.39,1.59,1.55,1.28,1.88$, and 0.26 whereas that of control mechanisms which includes conversion control right, veto management decision, performance options, preemptive control rights, warranty options, right to demand liquidation of assets and right to exit investment are equal to $1.55,0.64$, $1.61,1.14,1.37,0.71$, and 1.70 respectively. Additionally, Table 1 gives values on skewness, kurtosis as well as the Jarque-Bera test which helps to identify as to whether the data with respect to the variables follows a normal distribution. It

Table 1. Summary of descriptive statistics.

\begin{tabular}{lccccc}
\hline \multicolumn{1}{c}{ Variable } & Mean & Std. Dev. Skewness & Kurtosis Jarque-Bera test \\
\hline Dependent variable & & & & & \\
Venture capital fund & 7.63 & 1.91 & -2.41 & 10.48 & 329.93 \\
Independent variable (venture capital & instruments) & & & \\
Convertible redeemable preference & 5.84 & 0.21 & 0.75 & 1.64 & 16.83 \\
Preferred equity and debt & 9.56 & 2.39 & -0.49 & 2.46 & 5.22 \\
Preferred and common equity & 6.34 & 1.59 & -1.32 & 2.38 & 30.64 \\
Debt & 6.19 & 1.55 & -1.63 & 2.53 & 45.20 \\
Common equity & 5.12 & 1.28 & 1.25 & 2.64 & 26.58 \\
Perceived failure & 7.52 & 1.88 & -1.83 & 2.20 & 58.98 \\
Preferred equity & 2.22 & 0.26 & 1.18 & 2.04 & 27.05 \\
Independent variable (control mechanisms) & & & & \\
Conversion control right & 6.18 & 1.55 & -1.97 & 2.61 & 65.32 \\
Veto management decision & 2.54 & 0.64 & 1.13 & 2.32 & 23.21 \\
Performance options & 6.45 & 1.61 & -1.01 & 3.34 & 17.48 \\
Preemptive control rights & 4.57 & 1.14 & -0.77 & 3.58 & 11.28 \\
Put/Warranty options & 5.47 & 1.37 & -1.32 & 3.01 & 30.44 \\
Right to demand liquidation of assets & 2.84 & 0.71 & -1.07 & 2.59 & 19.78 \\
Right to exit the investment & 6.78 & 1.70 & -1.46 & 2.68 & 35.95 \\
\hline & & & & & \\
\hline
\end{tabular}


can therefore be deduced that the dependent variable together with independent variables Preferred equity and debt, Preferred and common equity, Debt, perceived failure under venture capital instruments and Conversion control right, Performance options, Preemptive control rights, Put/Warranty options, right to demand liquidation of assets, right to exit the investment also under control mechanisms are negatively skewed, flattering to the left as compared to the normal distribution. Also, the variables Convertible redeemable preference, Common equity, and Preferred equity as independent variables under venture capital instruments as well as Veto management decision under control mechanisms are positively skewed, flattering to the right. The kurtosis values of the dependent variable and the independent variables Performance options and Preemptive control rights as control mechanisms are higher than the normal values suggesting that the kurtosis curve is leptokurtic whereas the kurtosis values for preferred equity and debt, Debt, Common equity, Conversion control right, Right to demand liquidation of assets, and Right to exit the investment are approximately equal to the normal value suggesting these distributions are mesokurtic. On the other hand, the values of the kurtosis per the variables Convertible redeemable preference, Preferred and common equity, perceived failure, preferredequity, and Veto management decision are less than the normal value meaning the kurtosis curve for these variables is platykurtic. Generally, the normal value of the skewness is "zero" and that of kurtosis is "three" when the observed series is normally distributed. The result per the kurtosis ad the skewness for the various variables used in the study is in line with the Jarque-Bera test statistics in which all its values are not approximately zero or exactly zero. The JB test is used to determine whether the given series is normally distributed or not, with the null hypothesis that the series follows a normal distribution against the alternative hypothesis that the series is not normally distributed. The result from the JB test therefore rejects the null hypothesis that the series is normally distributed. Therefore, the series is not normally distributed.

This study further tests for multicolinearity among the independent variables using the VIF and Tolerance. Table 2 therefore shows the multicolinearity test results with respect to the independent variables used in the study. The VIF values are much less than 10 whilst the values of the tolerance on the other hand are also more than 0.2 . This therefore implies that, there exist no multicolinearity among the variables in both multiple linear regression models in Equation (2) and Equation (3) when growth of venture capital fund is used as the dependent variable.

Since there exists no multicolinearity in the multiple linear regressions specified in the study we went further to estimate the effect of both venture capital instruments and control mechanisms on the growth of venture capital in the next section.

\subsection{Modeling VFC Growth with Venture Capital Instruments}

The main objective of this study is to discover the relationship between each 
Table 2. Multicolinearity test using VIF and Tolerance.

\begin{tabular}{lcc}
\hline \multicolumn{1}{c}{ Independent variables } & VIF & Tolerance \\
\hline Venture capital instruments & & \\
Convertible redeemable preference & 8.25 & 0.47 \\
Preferred equity and debt & 5.21 & 0.76 \\
Preferred and common equity & 1.77 & 0.83 \\
Debt & 1.89 & 0.88 \\
Common equity & 4.28 & 0.82 \\
Perceived failure & 9.17 & 0.75 \\
Preferred equity & 6.44 & 0.56 \\
Control mechanisms & & \\
Conversion control right & 4.37 & 0.95 \\
Veto management decision & 2.13 & 0.59 \\
Performance options & 4.16 & 0.61 \\
Preemptive control rights & 4.60 & 0.42 \\
Put/Warranty options & 2.97 & 0.30 \\
Right to demand liquidation of assets & 2.12 & 0.36 \\
Right to exit the investment & 2.25 & 0.44 \\
\hline
\end{tabular}

Note: the values of both the VIF and Tolerance are based on the dependent variable (Venture capital fund). The VIF values are below 10 and that of Tolerance are below 0.2 .

individual predictive variable and the dependent variable. As such this section specifically estimates effect of the each of the venture capital instruments on the growth of venture capital fund. By using the stepwise method of multiple regression the following venture capital instruments were examined; preferred equity and debt, convertible redeemable preference, preferred and common equity, debt, common equity, perceived failure and preferred equity.

In order to examine the effects of these variables on the growth of venture capital fund, the goodness of fit as well as significance of the overall model which includes growth of venture capital fund as the dependent variable and venture capital instruments as predictive variables was assessed using both the model summary as well as the analysis of variance (ANOVA) test respectively. Table 3 therefore shows results based on the model summary. The R-value given in the table measures the strength of correlation between the response variable and predictive variables. The R-value which is 0.852 indicates a strong positive correlation between growth of venture capital and venture capital instruments. Additionally, results from the model summary gives the value of R-square (coefficient of determination) as 0.675 which implies that, about $67.5 \%$ of the variability in the dependent variable (growth of venture capital) is explained by the predictive variables (venture capital instruments). By referring to the adjusted $\mathrm{R}$-squared value (0.572), there is an indication that about $57.2 \%$ of the R-squared 
Table 3. Model summary.

\begin{tabular}{ccccc}
\hline Model & R-value & R-square value & Adj. R-square & Std. error of the estimate \\
\hline 1 & 0.852 & 0.675 & 0.572 & 10.984 \\
\hline
\end{tabular}

value is corrected so as to produce a better estimate of the true population value since the R-square value in the sample tends to overestimate the true population. The results based on the model summary considering the R-value, R-squared value and the adjusted $\mathrm{R}$-squared value generally indicates that, the model is appropriate and a good fit.

In order to assess the overall significance of the model with venture capital instruments as the predictive variables, it is necessary to look at the results from the analysis of variance presented in Table 4 . The ANOVA test the null hypothesis that the R-value in the population is equal to zero meaning there is no significant relationship between the response variable (growth of venture capital) and independent variables (venture capital instruments). The results from the Table 4 give an F-value of 21.187 and a significant value of 0.000 which is less than the $5 \%$ level of significance for the regression. This therefore gives the implication that, the model which includes growth of venture capital fund as dependent variable and venture capital instruments as the predictive variables is significant, leading to the rejection of the null hypothesis. This further implies that there exists a significant relation between the response variable (growth of venture capital) and explanatory variables (venture capital instruments).

Having confirmed that the regression model with growth of venture capital as dependent variable and venture appropriate and significantly fit, we further estimated the model in order to determine the significant effect of each of the independent variables (venture capital instruments) on the response variable (growth of venture capital fund). The results based on the rate of contribution of each of the explanatory variables together with their respective probability values are illustrated in Table 5. The table additionally provides the unstandardized and standardized coefficients of all the seven independent variables regarded as venture capital instruments included in the model as illustrated in Equation (2). In order to compare the level of importance per the contribution of each independent variable to the dependent variable (growth of venture capital), the "Beta" values under the column "standardized coefficients" must be looked at. Hence by comparing the values of the various independent variables under the column "standardized coefficients" it can be deduced that, the variable "preferred equity and debt" had the highest beta value (0.582). This means that, the aforementioned variable among the other venture capital instruments makes the strongest contribution to explaining the dependent variable (growth of venture capital) when the variance explained by the other variables in the regression model are controlled for. This is followed by the variable "convertible redeemable preference" which made the next strongest contribution with a beta value of 0.512 whilst the variable "common equity" when all negative sings are ignored made the least contribution amongst the other variables with a beta value of 
Table 4. Analysis of Variance (ANOVA).

\begin{tabular}{cccccc}
\hline Model & Sum of squares & df & Mean square & F-statistic & Sig-value \\
\hline Regression & 313.098 & 6 & 52.183 & 21.187 & 0.000 \\
Residual & 231.563 & 94 & 2.463 & & \\
Total & 544.661 & 100 & & & \\
\hline
\end{tabular}

Table 5. Evaluation of the independent variables (venture capital instruments).

\begin{tabular}{cccccc}
\hline Model & \multicolumn{2}{c}{$\begin{array}{c}\text { Unstandardized } \\
\text { coefficients }\end{array}$} & $\begin{array}{c}\text { Standardized } \\
\text { coefficients }\end{array}$ & & \\
& B & Std. error & Beta & t-value & Sig.-value \\
\hline (constant) & 1.794 & 0.159 & & 11.255 & 0.000 \\
Convertible redeemable preference & 0.051 & 0.036 & 0.512 & 13.367 & 0.000 \\
Preferred equity and debt & 0.222 & 0.054 & 0.582 & 17.211 & 0.000 \\
Preferred and common equity & -0.217 & 0.059 & 0.314 & 3.675 & 0.000 \\
Debt & -0.117 & 0.043 & -0.259 & -2.726 & 0.257 \\
Common equity & 0.004 & 0.049 & 0.009 & 0.088 & 0.930 \\
Perceived failure & -0.70 & 0.042 & -0.112 & -1.682 & 0.094 \\
Preferred equity & 0.064 & 0.004 & 0.103 & 1.552 & 0.124 \\
\hline
\end{tabular}

Note: Dependent variable: Growth of venture capital.

0.009. Table 5 further helps in determining the variables that made significant contribution to the dependent variable under the column labeled "sig-value (significant value). From this column, it can be deduced that, among the variables included in the model, only three (3) variables which includes convertible redeemable preference, preferred equity and debt and preferred and common equity contributed significantly to the growth of venture capital fund. All these significant variables interestingly had positive beta values which as such gives the indication that, increase in these variables (convertible redeemable preference, preferred equity and debt and preferred and common equity) will significantly increase the growth of venture capital funds of venture capital firms in Ghana.

\subsection{Modeling VFC Growth with Control Mechanisms}

After assessing the effect of the various venture capital instruments on the growth of venture capital fund, the study went further to assess the various effects of some control mechanisms as well by estimating the regression model in Equation (3). The variables used as control mechanisms in this model included conversion control right, veto management decision, performance options, preemptive control rights, warranty options, right to demand liquidation of assets and right to exit investment. The model summary from Table 6 per this regression model with growth of VCF still as the dependent variable and control mechanisms as predictive variables reveled that, there is a strong positive correlation between the dependent variable and the independent set of variables given an R-value of 0.742 . A substantial amount of variation (69.4\%) in the dependent 
variable was also found to be explained by the explanatory variables (control mechanisms) whereas the corrected portion of the R-squared value (Adjusted R-squared) which gives the correct estimation of the true population from Table 6 based on the regression analysis is obtained as 0.604 . In summary the aforementioned statistics with respect to the R-value, R-squared value and the Adjusted $\mathrm{R}$-squared value gives indication that the regression model with control mechanism as explanatory variables is also appropriate and a good fit as well.

The overall significance of this model as illustrated in Equation (3) was also assessed with the help of the analysis of variance (ANOVA) test. Results from the ANOVA test as presented in Table 7 with respect to the regression gives a value of F-statistic as 32.415 with a significant value of 0.000 which far less than the level of significance of $5 \%$. This therefore points out that that, the regression model with growth of VCF as the dependent variable and control mechanisms as the set of independent variables is significant, thus there exist a s significant relationship.

After the evaluating the significance of the regression model using the model summary results and the ANOVA test, we additionally investigated which of the independent variables (control mechanisms) included in the model contributed more and significantly to the dependent variable (growth of venture capital fund). Per the results from Table 8 under "standardized coefficients" it is revealed that the

Table 6. Model summary.

\begin{tabular}{ccccc}
\hline Model & R-value & R-square value & Adj. R-square & Std. error of the estimate \\
\hline 1 & 0.852 & 0.675 & 0.572 & 10.984 \\
\hline
\end{tabular}

Table 7. Analysis of Variance (ANOVA).

\begin{tabular}{cccccc}
\hline Model & Sum of squares & df & Mean square & F-statistic & Sig-value \\
\hline Regression & 210.061 & 6 & 35.010 & 32.415 & 0.000 \\
Residual & 101.525 & 94 & 1.080 & & \\
Total & 311.586 & 100 & & & \\
\hline
\end{tabular}

Table 8. Evaluation of the independent variables (control mechanisms).

\begin{tabular}{cccccc}
\hline Model & \multicolumn{2}{c}{$\begin{array}{c}\text { Unstandardized } \\
\text { coefficients }\end{array}$} & $\begin{array}{c}\text { Standardized } \\
\text { coefficients }\end{array}$ & & \\
& B & Std. error & Beta & t-value & Sig.-value \\
\hline (constant) & 1.730 & 0.521 & & 4.383 & 0.000 \\
Conversion control right & 1.513 & 0.403 & 0.295 & 3.758 & 0.000 \\
Veto management decision & -0.887 & 0.396 & -0.157 & -0.238 & 0.126 \\
Performance options & 1.012 & 0.337 & 0.224 & 3.002 & 0.003 \\
Preemptive control rights & -0.206 & 0.307 & -0.029 & -0.671 & 0.502 \\
Put/Warranty options & 0.172 & 0.075 & 0.392 & 2.303 & 0.000 \\
Right to demand liquidation of assets & -1.695 & 0.512 & -0.053 & -0.210 & 0.617 \\
Right to exit the investment & -1.171 & 0.375 & -0.158 & -0.277 & 0.448 \\
\hline
\end{tabular}

Note: Dependent variable: Growth of venture capital. 
variables conversion of control rights, performance options and warranty option are the control mechanisms among the others that contributes significantly to growth of venture capital in venture capital firms in Ghana. These significant contributing control mechanisms interestingly had positive beta values indicting their respective rates of contribution will definitely increase the growth of venture capital fund with Warranty option having the highest contribution (beta = 0.392 ) followed by conversion control right (beta $=0.295$ ) and then performance options (beta $=0.2424)$.

\subsection{Diagnostic Tests}

Diagnostic tests are very important for checking the model's validity with respect to interpretation. The diagnostic tests in this section include tests for the residuals which are normality test, and serial correlations, heteroscedasticity.

\section{Normality, Serial Correlations and Heteroscedasticity Tests}

The diagnostic check for the models used this study gives the indication that the models are valid for interpretation with no serial correlation and heteroscedasticity in residuals. Additionally, the residuals are normally distributed around the mean. Table 9 therefore shows the test results.

\section{Conclusions}

The venture capital industry particularly is a good example of an institution that prides itself on nursing companies, rather than financing them. Venture capitalists add value to their companies by providing a variety of services; they help shape strategies, provide technical and commercial advice and attract key personnel as well. But the main challenge for start-up businesses is the lack of opportunities in securing funds through traditional investment sources such as banks. While some notable effort has been made to sustain venture capital financing to the SME sector, progress over the last decade has been slow, with limited impact. In this study therefore, we examined the effect of seven (7) venture capital instruments as well as seven (7) control mechanisms on the growth

Table 9. Diagnostic tests.

\begin{tabular}{cc}
\hline Model 1 & \\
\hline Diagnostic tests & Test statistic \\
\hline Serial correlation & $\mathrm{F}=0.0429(0.838)$ \\
Normality test & $\chi^{2}($ Chi-square $)=3.372(0.185)$ \\
Heteroscedasticity & $\mathrm{F}=0.962(0.531)$ \\
\hline Model 2 & $\mathrm{F}=0.0619(0.415)$ \\
\hline Serial correlation & $\chi^{2}(\mathrm{Chi}-$ square $)=5.087(0.335)$ \\
Normality test & $\mathrm{F}=0.931(0.510)$ \\
\hline
\end{tabular}

Note: Numbers in the parenthesis are probability values. 
of venture capital fund by employing a stepwise multiple linear regression model. With the help of VIF and Tolerance multicolinearity tests, we established no multicolinearity among the explanatory variables, which include the venture capital instruments and control mechanisms. The results from the regression analysis also suggested that, there exists strong positive and significant relationship between growth of venture capital fund and the two distinct sets of independent variables (instruments of venture capital and control mechanisms). However, the venture capital instruments; convertible redeemable preference, preferred equity and debt and preferred and common equity contributed positively and significantly to growth of venture capital fund whilst conversion of control rights, performance options and warranty option were the control mechanisms that positively and significantly contributed to growth of venture capital fund. We therefore evaluated that, for the growth of venture capital fund to increase, venture capital instruments which include convertible redeemable preference, preferred equity and debt and preferred and common equity and control mechanisms such as conversion of control rights, performance options and warranty option must be considered.

\section{Conflicts of Interest}

The authors declare no conflicts of interest regarding the publication of this paper.

\section{References}

[1] Ghana Venture Capital Trust Fund (2013) Annual Report for 2012. Venture Capital Trust Fund, Ghana. http://www.venturecapitalghana.com.gh/

[2] Frimpong, F.A. (2008) Assessing the Prospects of Venture Capital Finance in Ghana, The Views and Perception of SMEs in the Greater Accra Region. MBA Thesis, KNUST School of Business, Kumasi.

[3] Nkusu, M. (2011) Nonperforming Loans and Macro Financial Vulnerabilities in Advanced Economies. IMF Working Papers, 1-27. https://doi.org/10.5089/9781455297740.001

[4] Alperovych, Y., Georges, H. and Fabrice, L. (2015) How Does Governmental Versus Private Venture Capital Backing Affect a Firm's Efficiency? Evidence from Belgium. Journal of Business Venturing, 30, 508-525. https://pdfs.semanticscholar.org/9291/39381993163a3be99e29556cdfae926b3f31.pdf https://doi.org/10.1016/j.jbusvent.2014.11.001

[5] Ghana Venture Capital Trust Fund (2014) Venture Capital Trust Fund, Ghana. http://www.venturecapitalghana.com.gh

[6] Mensah, S. (2004) A Review of SME Financing Schemes in Ghana. A Presentation at the UNIDO Regional Workshop of Financing SMEs, Daily Graphic, Accra, 15-16 March 2004, 21.

[7] Anokye-Yeboah, W. (2009) Venture Capital Financing in Ghana: Challenges and prospects. MBA, Ghana, KNUST School of Business.

[8] Agyeman, S.K. (2010) Challenges Facing Venture Capitalists in Developing Countries: An empirical Study about Venture Capital Industry in Ghana. Master's Thesis, Umeå School of Business, Umeå. 
[9] Bertoni, F., Massimo, G. and Luca, G. (2011) Venture Capital Financing and the Growth of High-Tech Start-Ups: Disentangling Treatment from Selection Effects. Research Policy, 40, 1028-1043. https://doi.org/10.1016/j.respol.2011.03.008

[10] Gompers, P., Kovner, A., Lerner, J. and Scharfstein, D. (2004) Venture Capital Investment Cycles: The Role of Experience and Specialization. (Unpublished Working Paper)

[11] Pearce, R. and Barnes, S. (2006) Raising Venture Capital. John Wiley and Sons, Ltd., West Sussex. https://doi.org/10.1002/9781118673416

[12] Agyemang, D. (2009) Venture Capital Financing in Ghana: Assessing Knowledge Base of Small and Medium Scale Enterprises in Kumasi Metropolis. MBA. Ghana, KNUST School of Business.

[13] Boateng, A. (2010) Venture Capital Financing. Daily Graphic, 27 January 2010, 33.

[14] Frederiksen, Ø. (1997) Venture Capital Firms Relationship and Cooperation with Entrepreneurial Companies. Linköping Studies in Science and Technology, Thesis No. 625, Linköping University, Linköping.

[15] Tyebjee, T.T. and Bruno, A.V. (1984) A Model of Venture Capitalist Investment Activity. Management Science, 30, 1051-1066. https://doi.org/10.1287/mnsc.30.9.1051

[16] Jonava, I. (2009) Optimizing Portfolio Valuations. Seattle Press, USA.

[17] Mokaddem, L. (2006) ADB Initiative: African Women in Business, SME Support and Access to Finance Facilitation, A Paper Presented at the Global Summit for Women, Cairo 9-12 June 2006.

[18] Grube, S.B. (2012) Tax Policy, Venture Capital, and Entrepreneurship. Journal of Public Economics, 87, 175-203.

[19] Tornell, D.F. (2010) Keep the Government Out of Venture Capital. Issues in Science and Technology, 9, 61-68.

[20] Hellmann, T. (2011) Developing a Venture Capital Industry. Comments prepared for the World Development Report Study Conference. Villa Boersig, Berlin. http://www.turkvca.org/articles/hellman000201.pdf

[21] Szerb, L. and Varga, A. (2002) High Tech Venture Capital Investment in A Small Transition Country: The Case of Hungary. Paper presented at the International Conference on the Theme Jointly Organized by UNU/INTECH and EU-DG Research at Brussels, 7-8 November 2002.

[22] Mogire, B. (2015) Public Versus Private Venture Capital: Seeding or Crowding Out? A Pan-European Analysis. Journal of Business Venturing, 18, 81-104.

[23] Judges, K. and Muller, R. (2005) A Respective Look as our Cooking Understanding of Project Success, Project Management Journal, 36, 19-31. https://doi.org/10.1177/875697280503600403

[24] Triantis, B. (2002) The Relationship Between Venture Capitalists and Managers in New Firms: Determinants of Contractual Covenants, Managerial Finance, 20, 9-30.

[25] Kirilenko, S. (2001) Raising Venture Capital. John Wiley and Sons, Ltd., West Sussex.

[26] Cuny, C. and Talmor, K. (2002) Profitability of Venture Capital Investment in Europe and the United States. Number 245. http://ec.europa.eu/economy_finance/publications/publication792_en.pdf

[27] Cumming, T. and Macintosh, M. (2000) The Interaction Between Product Market and Financing Strategy: The Role of Venture Capital. Review of Financial Studies, 13, 959-984. https://doi.org/10.1093/rfs/13.4.959 